\title{
Meat starter cultures: Isolation and characterization of lactic acid bacteria from traditional sausages
}

\author{
É. Laslo ${ }^{1}$ \\ É. György ${ }^{2}$ \\ e-mail: lasloeva@uni.sapientia.ro \\ e-mail: gyorgyeva@uni.sapientia.ro
}

\author{
A. Czikó ${ }^{2}$ \\ e-mail: czikoattila@gmail.com
}

${ }^{1}$ Sapientia Hungarian University of Transylvania (Cluj-Napoca, Romania),

Faculty of Economics, Socio-Human Sciences and Engineering,

Department of Bioengineering, RO-530104 Miercurea Ciuc, 1 Libertăţii Sq.

${ }^{2}$ Sapientia Hungarian University of Transylvania (Cluj-Napoca, Romania),

Faculty of Economics, Socio-Human Sciences and Engineering,

Department of Food Science, RO-530104 Miercurea Ciuc, 1 Libertăţii Sq.

\begin{abstract}
Fermented meat products represent an important segment of our alimentation. Obtaining these products is based on beneficial microorganism activity. In the case of traditional food products, these are commercial starters or autochthonous microflora. Fermentation of raw materials is mainly done by sugar metabolization of lactic acid bacteria (LAB). In addition, these microorganisms can have other beneficial properties too such as probiotic properties, antimicrobial compound production abilities, etc.

In order to meet consumer demands, starter cultures are continuously developed to produce high-quality, healthy, and tasty products, thus contributing to guaranteeing microbiological safety and to improving one or
\end{abstract}

Keywords and phrases: lactic acid bacteria, starter culture, fermentation, sausage 
more sensory characteristics, technological, nutritional, or health properties of the fermented products. The aim of our research is to determine the technological properties of autochthonous lactic acid bacteria originated from commercial fresh sausages in order to select and use them as potential starter cultures in the meat industry. In our work, we determined the relevant characteristics (such as salt tolerance, proteolytic activity, antimicrobial activity, and antibiotic resistance) of bacteria isolated from 16 fresh sausages. Based on our results, the studied bacterial isolates originated from sausages could be potentially used as autochthonous meat starter cultures.

\section{Introduction}

Some of the important preservation methods of meat products are fermentation and drying. Traditional sausage production has a long history, originating from the Mediterranean region. Worldwide, Europeans are the main consumers and producers of this type of fermented meat products. Over centuries, the environmental conditions, certain intrinsic factors, and tradition had an impact on the production of sausage and fermented meat (Zeuthen, 1995).

Traditional sausages are defined (Leroy et al., 2015) as meat products containing different meat mixtures with added spices and nitrite/nitrate salts, stuffed in casing, eventually smoked. The final product is obtained by a ripening process including fermentation and drying.

Depending on the sausage type, the fermentation is initiated by commercial starters or autochthonous microflora. Fermented meat products have several benefits (Singh et al., 2012; Bourdichon et al., 2012) such as enhanced nutritional and quality characteristics, are rich in essential amino and fatty acids, and are less perishable with an extended shelf life.

In fermentation, two groups of microorganisms play a key role, namely lactic acid bacteria (LAB) (counts of $10^{3}-10^{9} \mathrm{CFU} / \mathrm{g}$ ) and coagulase-negative Grampositive staphylococci (counts up to $10^{8} \mathrm{CFU} / \mathrm{g}$ ). In addition to these, less significant are eukaryotic microorganisms, yeasts, and moulds. Microbes and their enzymes are responsible for the complex biochemical changes in the meat matrix. LAB have an impact on the technological characteristics of the product and also influence microbiological stability. In sausages, bacterial starter culture strains determine the functional properties and safety aspects of the product. Acidification, flavour development, proteolytic activity, amino acid metabolism, antioxidant enzymes (catalase and superoxide dismutase), and ni- 
trate reduction all contribute to the formation of the final product. Regarding the safety of the starter culture, it should not possess biogenic amine production and acquired antimicrobial resistance. It also has to be free of enterotoxin determinants (Cocconcelli \& Fontana, 2014). During the metabolic activities, lactic acid (resulted from the fermentation of carbohydrates by LAB) reduces $\mathrm{pH}-$ level and thus contributes to safety, texture transformation, and acid taste development. Depending on the microflora, raw materials, and additives, the following metabolites are released in varying amounts: acetoin, pyruvic and acetic acid, ethanol, and carbon dioxide. Safety aspects result also from the bioprotective character of some of the LAB (Garriga \& Aymerich, 2015) as different antimicrobial natural peptides (bacteriocins) are produced by them. Furthermore, owing to probiotic properties, LAB may enhance the functional value of the fermented food.

Microbial ecology of fermented sausages could be considered as a complex and rich microbiological niche. Bacterial strains involved in fermentation and biochemical transformation could be characterized by robustness and flexibility. Acidification is a functional characteristic of the most frequently present species of the Lactobacillus genus. Lactobacillus sakei was the predominant species among the LAB isolated from different sausages prepared with altered technologies. Different genotypes of this bacteria were isolated, and they represent 55\% of all LAB (Garriga \& Aymerich, 2015). The main explanation of the fact that these bacteria harboured and adapted to the conditions is that they are able to use as energy source both carbohydrates and amino acids (Cocconcelli \& Fontana, 2015). Other species of the Lactobacillus genus were also detected: Lactobacillus plantarum, Lb. curvatus, and Lb. rhamnosus. Unlike in Europe, Pediococcus was a relevant member of the microbial ecology of sausages in the United States as it is mostly added as starter culture. Pediococcus acidilactici and P. pentosaceus are responsible also for acidification and are able to produce bacteriocins (Cocconcelli, 2007; Cocconcelli \& Fontana, 2014). The predominant Gram-positive, catalase-positive cocci are Staphylococcus saprophyticus, S. xylosus, S. succinus, and S. equorum. Different technological functions are related to this species due to the involvement of the fatty acid metabolism and amino acid catabolism in flavour development. Nitrate reduction leads to the red colour formation - for example, Kocuria varians is added for nitrate reduction (Selgas \& García, 2014) -, and catalase activity prevents lipid oxidation (Macedo et al., 2017).

Safer and functional foods are the current trends in food consumption. To satisfy consumer demands, there are certain innovative attempts, for example, in starter culture development. Besides product processing, environmen- 
tal factors also influence the metabolic activity of starter cultures. A current strategy in meat industry is the application of wild strains for standardized sausage fermentation. To meet this demand, selection criteria focus on naturally occurring strains from meat ecology with desired technological aspects and stress resistance (Corbo et al., 2017; Pereira et al., 2019).

The aim of the present study was to determine the technological properties of autochthonous lactic acid bacteria originated from commercial fresh sausages in order to select and use as potential starter cultures in the meat industry.

\section{Materials and methods}

\section{Isolation of lactic acid bacteria}

In the course of our work, more than 60 lactic acid bacteria were isolated on de Man, Rogosa, and Sharpe (MRS) agar from 16 different commercially available, traditionally processed, fresh sausages. Surface-sterilized (2 min in $72 \%$ ethanol) $10 \mathrm{~g}$ sausages were smashed in a sterile mortar and homogenized with $90 \mathrm{ml}$ physiological solution. From these samples, dilution series were prepared and an amount of $0.1 \mathrm{ml}$ from the homogenized mixture was spread on the surface of MRS agar medium and incubated at $37^{\circ} \mathrm{C}$ for $24 \mathrm{hrs}$ in aerobic conditions. The isolated bacteria were analysed for the most representative technological characteristics of LAB; the experiments were done in two replicates.

\section{Bacterial growth at different salt concentrations}

LAB isolates $0.1 \%(\mathrm{v} / \mathrm{v})$ were inoculated in MRS broth with different salt concentrations: 6.5\%, 8\%, and 10\% (Papamanoli et al., 2010). Bacterial growth was evaluated after incubation at $30^{\circ} \mathrm{C}$ for $48 \mathrm{hrs}$ as absorbance values at $630 \mathrm{~nm}$. Salt tolerance was expressed as growth index $\left(\mathrm{G}_{\mathrm{i}}\right)$ (Speranza et al., 2014), calculated from the formula:

$$
\mathrm{G}_{\mathrm{i}}=100 \cdot \frac{\mathrm{A}_{\mathrm{s}}}{\mathrm{A}_{\mathrm{c}}}
$$

where: $A_{s}$ - sample absorbance in the present of salt and $A_{c}-$ absorbance of the control. 
Bacterial growth at different temperatures

LAB isolates $0.1 \%(\mathrm{v} / \mathrm{v})$ were inoculated in MRS broth and incubated at three different temperatures: $20^{\circ} \mathrm{C}, 30^{\circ} \mathrm{C}$, and $37^{\circ} \mathrm{C}$. Bacterial growth was evaluated after incubation as absorbance values at $630 \mathrm{~nm}$.

Bacterial growth at different $p H$ values

LAB isolates $0.1 \%(\mathrm{v} / \mathrm{v})$ were inoculated in MRS broth adjusted to different pH values: 3, 4, 5 (Papamanoli et al., 2010). Bacterial growth was evaluated after incubation at $30^{\circ} \mathrm{C}$ for $48 \mathrm{hrs}$ as absorbance values at $630 \mathrm{~nm}$.

\section{Gas production}

Gas production of LAB isolates was detected in MRS broth containing inverted Durham tubes (Patil et al., 2010).

\section{Proteolytic activity}

Proteolytic activity of LAB isolates was determined with well diffusion method on modified skimmed milk agar medium ( $0.5 \%$ casein, $0.25 \%$ yeast extract, $0.1 \%$ dextrose, skim milk powder 2.8\%, and agar 1.5\%). $50 \mu \mathrm{l}$ of supernatant LAB isolates were inoculated in the 8-mm-diameter hole in the modified skimmed milk agar medium and incubated at $37^{\circ} \mathrm{C}$ for $48 \mathrm{hrs}$. Proteolytic activity was determined in accordance with the measured clear zone diameter surrounding each culture.

\section{Antibacterial activity}

The antibacterial activity of LAB isolates was determined with agar diffusion method on different pathogenic and spoilage indicator strains (from the microbiological laboratory of the University) as Micrococcus luteus, Bacillus cereus, Bacillus subtilis, Escherichia coli, Staphylococcus aureus, and Proteus vulgaris. These bacterial cultures were grown for $24 \mathrm{hrs}$ at $28^{\circ} \mathrm{C}$ and $37^{\circ} \mathrm{C}$ on Nutrient agar. $0.1 \mathrm{ml}$ bacterial suspension (with $\mathrm{OD}=1$ ) was spread in the case of each bacteria with surface streaking on Nutrient agar (meat extract 1 $\mathrm{g}$, yeast extract $2 \mathrm{~g}$, peptone $5 \mathrm{~g}, \mathrm{NaCl} 5 \mathrm{~g}$, agar $15 \mathrm{~g}$, distilled water $1000 \mathrm{ml}$ ), and $50 \mu \mathrm{l}$ of the cell-free supernatant of LAB isolates (centrifuged at 14,000 $\mathrm{rpm}$, for $5 \mathrm{~min}$ ) was dropped in the 8 -mm-diameter hole cut with the help of a sterile test-tube. The inoculated Petri dishes were incubated at $28^{\circ} \mathrm{C}$ 
and $37^{\circ} \mathrm{C}$. The antibacterial effect of the tested LAB isolates was expressed in accordance with the diameter of the inhibition zone.

\section{Antibiotic susceptibility}

Determination of antimicrobial susceptibilities of LAB isolates was realized according to the guidelines reported in EFSA (2012). For the assessment of the susceptibility to ampicillin, gentamicin, streptomycin, erythromycin, chloramphenicol, and kanamycin, two-fold serial dilutions were realized ranging from 0 up to $128 \mu \mathrm{g} / \mathrm{mL}$, with the exception of erythromycin $(1-2 \mu \mathrm{g} / \mathrm{mL})$ in MRS broth (Laslo et al., 2015).

\section{$3 \quad$ Results and discussions}

Enumeration of viable LAB counts were done from 16 different, commercially available, traditionally processed sausage samples. The viable count of LAB in tested samples ranged between $3.3 \cdot 10^{1}$ and $5.8 \cdot 10^{5} \mathrm{CFU} / \mathrm{g}$. In three samples, the viable count of LAB was very low, perhaps because these samples underwent heat treatment during the production process. Based on colony size and morphology, 35 colonies were picked from MRS agar for further characterization.

Salt content is one of the major environmental factors that has an impact on bacterial strains involved in fermentation. Salt is used in processed meat to develop the taste and extend shelf life. Almost all of the tested LAB isolates were able to grow in the presence of $6.5 \%$ salt. According to Cruxen et al. (2019), salt tolerance is a selection criterion in the case of native isolates. Our results regarding the tolerance of $6.5 \% \mathrm{NaCl}$ are in concordance with those reported by Almeida et al. (2015). A higher salt concentration decreased the growth of the isolates, with an exception, as found also by Aina (2019). Lb. plantarum originated from artisanal sausage could survive the presence of $7 \%$ $\mathrm{NaCl}$, whereas Staphylococcus spp. tolerated salt concentration up to $15 \%$ (Cruxen et al., 2019).

The growth index (Fig. 1) varied in the range of $4-99 \%$, and $74 \%$ of the isolates showed excellent growth. With the exception of $11 \%$ of LAB isolates, all of them had a higher growth index. In the presence of $8 \%$ salt, $26 \%$ of the isolated LAB were able to grow well, $37 \%$ of the isolated bacteria were inhibited, and $37 \%$ of bacterial isolates showed medium growth. The growth index ranged between $2.17 \%$ and $92.83 \%$. In the presence of $10 \%$ salt, most 
of the isolates were inhibited. Only $20 \%$ of the isolates showed mild growth, with a growth index between 2 and $22.64 \%$.

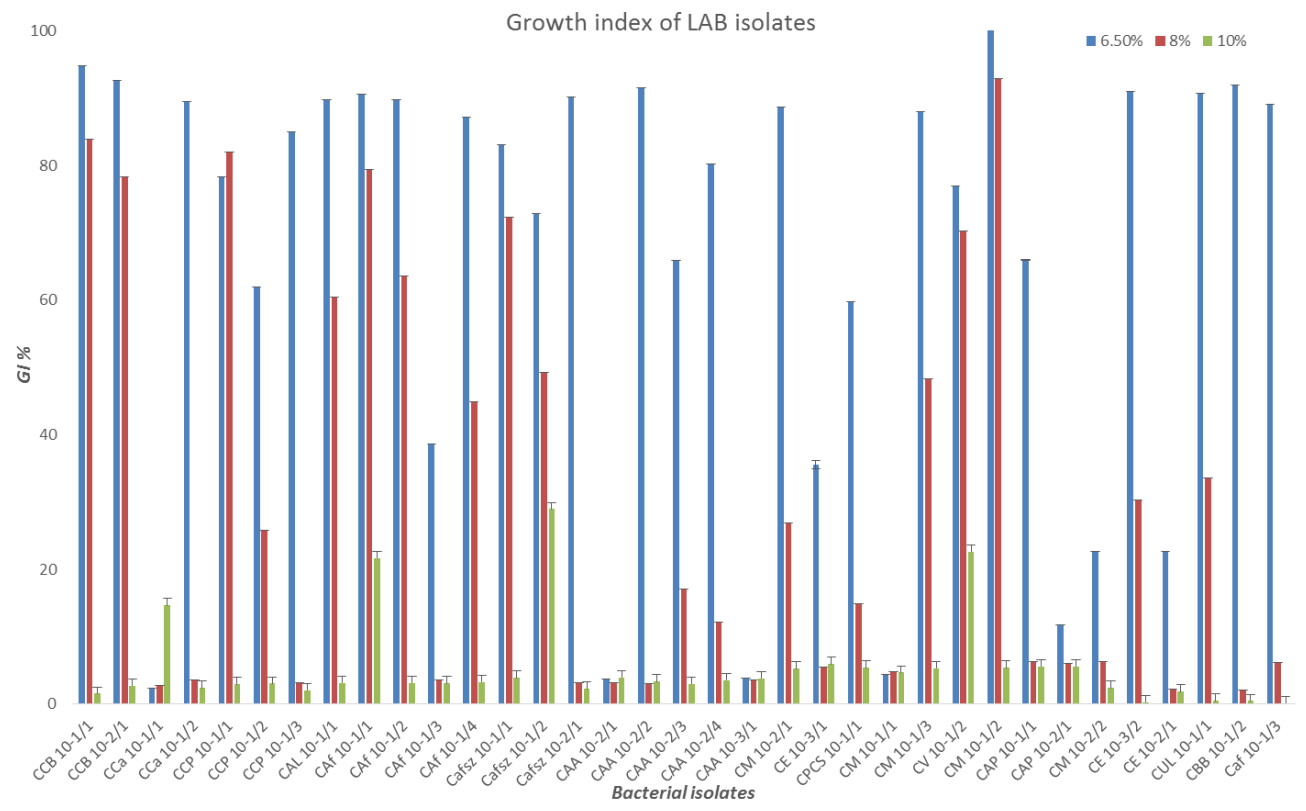

Figure 1: Growth index of LAB isolates in the presence of different salt concentrations

Further, the most beneficial strains were selected. The results of proteolytic activity for the most representative strains are presented in Table 1. All selected LAB showed proteolytic activity on the assayed medium agar. The clear zone diameter ranged in the interval of $13-17.33 \mathrm{~mm}$. The benefits of proteolytic activity consist in texture and flavour development, contribution to water release through enhancing the drying process, and that via hydrolysation different peptides and volatile compounds are released, which serves as aroma precursor. It was demonstrated that different LAB, such as Pediococcus pentosaceus or Lactobacillus curvatus, originated from sausages hydrolysed sarcoplasmic proteins, generating different volatile compounds (Cruxen et al., 2019). Different bioactive peptides derived from the peptidase and aminopeptidase activity of starter cultures are involved in functional food development (Arihara, 2014). 
Table 1: Proteolytic activity of the isolates

\begin{tabular}{cr}
\hline Bacterial isolates & Clear zone $\mathbf{m m}$ \\
\hline CCB 10-1/1 & $13.33 \pm 1.5$ \\
CCB 10-2/1 & $14.33 \pm 0.6$ \\
CCP 10-1/1 & $14.33 \pm 1.5$ \\
CAL 10-1/1 & $13.2 \pm 1$ \\
CAf 10-1/1 & $15.67 \pm 3.2$ \\
CAf 10-1/2 & $16.33 \pm 2.1$ \\
CAf $10-1 / 4$ & $15 \pm 1$ \\
Cafsz 10-1/1 & $15 \pm 1$ \\
Cafsz 10-1/2 & $16 \pm 2$ \\
CM $10-2 / 1$ & $16.07 \pm 2.1$ \\
CM 10-1/3 & $17.33 \pm 3.06$ \\
CV 10-1/2 & $14.33 \pm 1.53$ \\
CM 10-1/2 & $16.67 \pm 3.1$ \\
CE 10-3/2 & $13 \pm 1$ \\
CUL 10-1/1 & $14 \pm 2$ \\
\hline
\end{tabular}

Table 2: Antimicrobial effect of bacterial isolates on Gram-positive bacteria

\begin{tabular}{llcccc}
\hline & \multirow{2}{*}{ LAB isolates } & \multicolumn{5}{c}{ Inhibition diameter $(\boldsymbol{m m})$} \\
\cline { 3 - 6 } & & M. luteus & B. cereus & B. subtillis & S. aureus \\
\hline 1 & CCB 10-1/1 & - & $11.33 \pm 0.58$ & $12.53 \pm 0.5$ & $11.67 \pm 0.58$ \\
2 & CCB 10-2/1 & $13.53 \pm 0.5$ & $13.20 \pm 0.2$ & $14.00 \pm 0.2$ & $13.73 \pm 0.64$ \\
3 & CCP 10-1/1 & - & $14.33 \pm 1.53$ & - & $16.33 \pm 1.53$ \\
4 & CAL 10-1/1 & - & $13.00 \pm 1$ & - & $14.33 \pm 1.53$ \\
5 & CAf 10-1/1 & - & $13.07 \pm 0.9$ & $11.67 \pm 0.58$ & $12.40 \pm 0.53$ \\
6 & CAf 10-1/2 & $12.33 \pm 0.58$ & $14.33 \pm 1.53$ & $14.53 \pm 0.5$ & $15.60 \pm 0.53$ \\
7 & CAf 10-1/4 & - & $14.00 \pm 2$ & $8.80 \pm 0.2$ & $11.67 \pm 0.58$ \\
8 & Cafsz 10-1/1 & - & $13.07 \pm 1.01$ & $8.60 \pm 0.2$ & $11.67 \pm 0.58$ \\
9 & Cafsz 10-1/2 & - & - & $10.60 \pm 0.53$ & $10.60 \pm 0.53$ \\
10 & CM 10-2/1 & - & - & $13.87 \pm 0.31$ & $13.53 \pm 0.5$ \\
11 & CM 10-1/3 & $13.00 \pm 1$ & $14.40 \pm 0.87$ & $12.67 \pm 3.06$ & $14.00 \pm 2$ \\
12 & CV 10-1/2 & - & $11.00 \pm 1.0$ & - & $10.07 \pm 0.31$ \\
13 & CM 10-1/2 & - & - & - & $13.93 \pm 2.10$ \\
14 & CE 10-3/2 & - & $11.60 \pm 0.53$ & $11.67 \pm 0.58$ & $15.00 \pm 1.0$ \\
15 & CUL 10-1/1 & $20.13 \pm 1.28$ & $13.00 \pm 1.0$ & $13.33 \pm 1.15$ & $16.00 \pm 2.0$ \\
\hline & & & & &
\end{tabular}

The tested LAB isolates displayed different levels of bacteriostatic effects against the studied bacterial strains. Concerning Gram-positive bacteria, the most suppressive effect was detected in the case of Staphylococcus aureus, with a large inhibition zone of $16.63 \mathrm{~mm}$ in the case of the CCP 10-1/1 iso- 
late. The characterized LAB isolates from sausages exerted greater inhibitory effect against $S$. aureus in contrast with bacterial isolates from home-made fermented foods (Ren et al., 2018). In the case of the two Bacillus strains, the inhibition zone ranged between 11.40 and 14.40 (B. cereus) and between 8.6 and 14.53 (B. subtilis). The cell-free supernatant of CAf $10-1 / 2$ inhibited with a larger inhibition zone both Bacillus bacterial strains. The most effective bacteriostatic effect was observed in the case of CAf $10-1 / 2$. That isolate suppressed all the four tested Gram-positive bacteria with a large inhibition zone. LAB isolates exerted weak or no antibacterial activity against Micrococcus luteus. In concordance with our results, it has been shown that Micrococcus luteus was the most resistant bacteria (Evurani et al., 2018) and was not inhibited by Lactobacillus casei and Lb. brevis.

The antibacterial effect against the tested Gram-negative bacteria was not promising. The LAB isolates exerted weak suppressive effect against $P$. vulgaris. Only five isolates displayed antibacterial effect against these tested bacteria. According to Aruna et al. (2016), P. vulgaris - tested by them is resistant to bacteriocins. The largest inhibitory zones were observed in the case of CM 10-2/1. The inhibition zone was $13.00 \mathrm{~mm}$ in the case of E. coli and 14.33 in the case of P. vulgaris. The largest inhibition zone appears for E.coli: it was $14.47 \mathrm{~mm}$.

Table 3: Antimicrobial effect of bacterial isolates on Gram-negative bacteria

\begin{tabular}{llcc}
\hline & \multirow{2}{*}{$\boldsymbol{L A B}$ isolates } & \multicolumn{2}{c}{ Inhibition diameter $(\boldsymbol{m m})$} \\
\cline { 3 - 4 } & & $\boldsymbol{E}$ coli & $\boldsymbol{P .}$ vulgaris \\
\hline & & & \\
1 & CCB 10-1/1 & $12.33 \pm 0.58$ & - \\
2 & CCB 10-2/1 & $13.67 \pm 0.42$ & - \\
3 & CCP 10-1/1 & $13.33 \pm 0.58$ & - \\
4 & CAL 10-1/1 & $13.67 \pm 1.15$ & - \\
5 & CAf 10-1/1 & $10.00 \pm 1.00$ & - \\
6 & CAf 10-1/2 & $11.73 \pm 0.64$ & $11.67 \pm 0.58$ \\
7 & CAf 10-1/4 & - & - \\
8 & Cafsz 10-1/1 & - & - \\
9 & Cafsz 10-1/2 & - & $11.00 \pm 1.0$ \\
10 & CM 10-2/1 & $13.00 \pm 1.00$ & $14.33 \pm 1.53$ \\
11 & CM 10-1/3 & - & - \\
12 & CV 10-1/2 & - & - \\
13 & CM 10-1/2 & $10.60 \pm 0.4$ & - \\
14 & CE 10-3/2 & $14.47 \pm 0.5$ & $10.53 \pm 0.64$ \\
15 & CUL 10-1/1 & $11.00 \pm 1.0$ & $13.67 \pm 0.58$ \\
\hline
\end{tabular}


Fermented meat microbiota is made up of bacterial strains of Lactobacillus and Lactococcus genus with bacteriocinogenic features and biopreservative role (Castilho et al., 2019). Different strains from fermented meat are called bacteriocin producers: various $L$. sakei and L. curvatus strains, Pediococcus acidilactici strain MCH14, and S. xylosus strain SX S03/1 M/1/2 (Laranjo et al., 2017).

LAB exhibits a broad-spectrum antimicrobial activity due to various mechanisms. The antagonistic mechanisms of LAB are diverse due to the altered gene expression and molecular structure of bacterial strains. The inhibitory activity of LAB strains is associated with their primary metabolites such as organic acids, alcohol, and carbon dioxide. LAB also produce different compounds with antagonistic effect. It was shown that formic and benzoic acids, hydrogen peroxide, diacetyl, acetoin, and bacteriocins have a role in the suppression of different microorganisms. For the suppression of Gram-negative bacteria, the organic acids and hydrogen peroxide are presumed to be responsible, while in the case of Gram-positive bacteria proteinaceous compounds are the potential causes. Reduced $\mathrm{pH}$ contributes to the inactivation of bacterial cell as well. The weak acids entering the cell may cause the acidification of the cytoplasm, leading to different disorders in the metabolism, structure, and function of the bacterial cell (Olorunjuwon et al., 2013; Gao et al., 2019). The mode of action of the nisin is dual, consisting of pore formation in the membrane or disrupting cell wall synthesis, leading to bacterial cell death (Jozala et al., 2015).

From the isolated bacteria, 6 isolates showed $\mathrm{CO}_{2}$ production. In the manufacture of different meat products, homofermentative strains are used (Cocconcelli, 2007).

Almost all tested LAB isolates showed varying levels of growth at $\mathrm{pH} 4$ and pH 5 (data not shown). None of the tested bacterial strains showed activity at pH 3. According to Erkkilä and Petäjä (1999), most of the LAB isolated from meats has shown no decrease at $\mathrm{pH}$ 4. Our results also showed that the isolated strain was not able to grow at $3 \mathrm{pH}$. In the case of $\mathrm{pH} 4$ and 5, isolates showed the highest growth. The highest growth was detected at $\mathrm{pH} 5$, with the exception of two bacterial isolates: Cafsz 10-1/1 and CCB 10-1/1.

Based on the results of the growth assay carried out at different temperatures, it can be said that almost all isolates grew at $20^{\circ} \mathrm{C}$ (data not shown), with an OD value of 1.92 . As for 30 and $37^{\circ} \mathrm{C}$, the same results were obtained. At these two temperatures, the highest OD value was 2.02. From the assayed bacterial isolates, two LAB isolates (CAf 10-1/3, CCa 10-1/1) did not show growth at $20^{\circ} \mathrm{C}$. In the case of one isolate, the growth was observed at $30^{\circ} \mathrm{C}$. 
It was shown that $\mathrm{pH}$ and temperature influence the growth of lactic acid bacteria in different ways (Adamberg et al., 2003).

Table 4: Minimal inhibitory concentration in the selected LAB isolates in the case of the tested antibiotics

\begin{tabular}{|c|c|c|c|c|c|c|}
\hline Bacterial isolates & 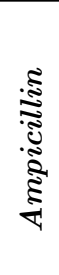 & 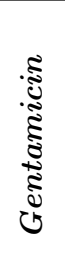 & 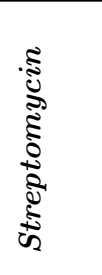 & 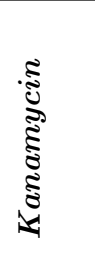 & 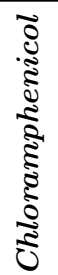 & 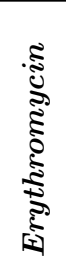 \\
\hline CCB $10-2 / 1$ & 4 & 8 & 64 & $>128$ & 8 & 2 \\
\hline CCP 10-1/1 & 4 & 8 & 32 & $>128$ & 8 & 2 \\
\hline CAL $10-1 / 1$ & 4 & 4 & 32 & $>128$ & 8 & 2 \\
\hline CAf $10-1 / 2$ & 4 & 64 & $>128$ & $>128$ & 8 & $>2$ \\
\hline CAf $10-1 / 4$ & 4 & 8 & 64 & $>128$ & 8 & 2 \\
\hline Cafsz $10-1 / 2$ & 4 & 64 & $>128$ & $>128$ & 16 & $>2$ \\
\hline CM 10-2/1 & 4 & 16 & 64 & $>128$ & 8 & $>2$ \\
\hline CV $10-1 / 2$ & 8 & 8 & 64 & $>128$ & 8 & 2 \\
\hline CE $10-3 / 2$ & 2 & 16 & 128 & $>128$ & 8 & 2 \\
\hline CUL 10-1/1 & 4 & 16 & 64 & $>128$ & 8 & 2 \\
\hline
\end{tabular}

LAB resistance towards antibiotics represents an emerging and serious food safety concern. The World Health Organization suggests that LAB used in food industry should be free of antibiotic resistance (Álvarez-Cisneros \& PonceAlquicira, 2018).

In the case of the most beneficial ten LAB isolates, the MICs of six antibiotics were determined. Based on the results, the differences in MIC values did not exceed one or two orders of dilution.

In the case of ampicillin, the MIC was $4 \mathrm{mg} / \mathrm{L}$ with the exception of two isolates, where it was 2 and $8 \mathrm{mg} / \mathrm{L}$. In the case of gentamicin, the MIC values ranged between 4 and $64 \mathrm{mg} / \mathrm{L}$, whereas the majority was equal with $8 \mathrm{mg} / \mathrm{L}$. The MIC values for streptomycin ranged between 32 and $128 \mathrm{mg} / \mathrm{L}$ with two exceptions, where the MIC was higher than the tested concentration. Also, with kanamycin, the tested isolates showed growth at the maximum tested concentration $(128 \mathrm{mg} / \mathrm{L})$. With the exception of one isolate, MIC was $8 \mathrm{mg} / \mathrm{L}$ for chloramphenicol. In the case of erythromycin, the MIC was $2 \mathrm{mg} / \mathrm{L}$ for seven LAB isolates, while the other isolates were growing at this concentration. Based on the results, the majority of the tested bacterial isolates showed susceptibility to ampicillin with the exception of one isolate. In general, it 
is considered that bacterial strains belonging to the Lactobacillus genus show sensitivity to the cell wall synthesis inhibiting penicillin and $\beta$-lactamase antibiotics (Gueimonde et al., 2013).

In the case of gentamycin, two isolates were resistant. Three of the tested isolates were found resistant to streptomycin. All tested isolates showed resistance to kanamycin and chloramphenicol. In LAB, the resistance type towards kanamycin, gentamycin, and streptomycin is intrinsic. The absence of cytochrome-mediated electron transport contributes to the formation of resistance to the aminoglycosidic antibiotics such as kanamycin and streptomycin (Narayanan \& Raghavan, 2019). Enzymatic deficiency or disabled enzymatic transport of aminoglycoside-modifying enzymes, such as N-acetyltransferases, O-phosphotransferases, and O-nucleotidyltransferases, results the above mentioned resistance (Álvarez-Cisneros \& Ponce-Alquicira, 2018).

All ten selected isolates showed resistance to erythromycin.

In concordance with our results, previous studies reported different LAB strains isolated from fermented sausages with multiple antibiotic resistance. $L$. plantarum, L. fermentum, and L. helveticus showed resistance to kanamycin, tetracycline, erythromycin, chloramphenicol, and to other antibacterial compounds (Patel et al., 2012). LAB strains originated from Portuguese and Italian sausages showed resistance towards streptomycin, gentamycin, chloramphenicol, erythromycin, etc. (Álvarez-Cisneros \& Ponce-Alquicira, 2018). Narayanan \& Raghavan (2019) suggested that the LAB of starter cultures show higher resistance against antibiotics and could be the store of resistance genes. In some cases, these genes are not expressed but can be transferred to other bacterial strains. The safety characterization of LAB is essential to avoid any risk of infection by using them (Borriello et al., 2003, Doron and Snydman, 2015).

\section{Conclusions}

Based on the results, it can be concluded that the lactic acid bacterial isolates originating from the autochthonous microbial ecology of fermented sausages showed positive technological properties. Regarding the assayed technological characteristics of isolates, these strains can be involved in the fermentation of sausages, playing an important role in the development of sensorial characteristics, texture, aroma formation, and the inhibition of different pathogenic microorganisms. For a successful and safe application of these isolates, further studies are needed to assess the safety of the strains to avoid bacteremia. Also, 
it is necessary to identify the isolates, determine their virulence factors, and the biogenic amine production capacity.

\section{References}

[1] K. Adamberg, S. Kask, T. M. Laht, T. Paalme, The effect of temperature and $\mathrm{pH}$ on the growth of lactic acid bacteria: A pH-auxostat study. International Journal of Food Microbiology, 85. 1-2. (2003) 171-183.

[2] A. T. Aina, Effect of sodium chloride $(\mathrm{NaCl})$ on the growth of Pediococcus acidilactici used for the improvement of nutritional and microbial quality of tsire: A Nigerian grilled meat product. Journal of Nutrition \& Food Sciences 7. 4. (2017) 1-4.

[3] W. L. G. Almeida Júnior et al., Characterization and evaluation of lactic acid bacteria isolated from goat milk. Food Control, 53. (2015) 96-103.

[4] K. Arihara, Probiotics (Chapter 18). In: F. Toldrá, Y. H. Hui, I. Astiasarán, J. G. Sebranek, R. Talon (ed.), Handbook of fermented meat and poultry. Wiley-Blackwell, Chichester (2015).

[5] B. Aruna, D. M. Srivalli, Isolation and characterization of bacteriocin producing lactic acid bacteria from fermented Bengal gram. International Journal of Pharmaceutical Science Invention, 5. 4. (2016) 41-46.

[6] Y. M. Álvarez-Cisneros, E. Ponce-Alquicira, Antibiotic resistance in lactic acid bacteria. In: Y. Kumar (ed.), Antimicrobial resistance. A global threat. IntechOpen, London. (2018).

[7] S. P. Borriello et al., Safety of probiotics that contain lactobacilli or bifidobacteria. Clinical Infectious Diseases, 36. 6. (2003) 775-780.

[8] F. Bourdichon et al., Food fermentations: Microorganisms with technological beneficial use. International Journal of Food Microbiology, 154. 3. (2012) 87-97.

[9] N. P. A. Castilho, M. Colombo, L. L. Oliveira, S. D. Todorov, L. A. Nero, Lactobacillus curvatus UFV-NPAC1 and other lactic acid bacteria isolated from calabresa, a fermented meat product, present high bacteriocinogenic activity against Listeria monocytogenes. $B M C M i$ crobiology, 19. 63. (2019) 1-13. 
[10] P. S. Cocconcelli, C. Fontana, Bacteria (Chapter 14). In: F. Toldrá, Y. H. Hui, I. Astiasarán, J. G. Sebranek, R. Talon (ed.), Handbook of fermented meat and poultry. Wiley-Blackwell, Chichester (2015).

[11] P. S. Cocconcelli, Starter cultures: Bacteria. In: F. Toldrá, Y. H. Hui, I. Astiasarán, J. G. Sebranek, R. Talon (eds.), Handbook of fermented meat and poultry. Blackwell Publishing, Oxford (2007).

[12] M. R. Corbo, A. Racioppo, N. Monacis, B. Speranza, Commercial starters or autochthonous strains? That is the question. In: B. Speranza, A. Bevilacqua, M. R. Corbo, M. Sinigaglia (eds.), Starter cultures in food production. Wiley-Blackwell, Chichester (2017).

[13] C. E. D. S. Cruxen et al., Selection of native bacterial starter culture in the production of fermented meat sausages: Application potential, safety aspects, and emerging technologies. Food Research International, 122. (2019) 371-382.

[14] S. Doron, D. R. Snydman, Risk and safety of probiotics. Clinical Infectious Diseases, 60. 2. (2015) 129-134.

[15] EFSA, Guidance on the assessment of bacterial susceptibility to antimicrobials of human and veterinary importance. EFSA Journal, 10. 6. (2012) 2740.

[16] S. Erkkilä, E. Petäjä, Screening of commercial meat starter cultures at low $\mathrm{pH}$ and in the presence of bile salts for potential probiotic use. Meat Science, 55. 3. (2000) 297-300.

[17] M. Garriga, T. Aymerich, The microbiology of fermentation and ripening (Chapter 13). In: F. Toldrá, Y. H. Hui, I. Astiasarán, J. G. Sebranek, R. Talon (ed.), Handbook of fermented meat and poultry. Wiley-Blackwell, Chichester (2015).

[18] M. Gueimonde, B. Sánchez, G. de los Reyes-Gavilán, A. Margolles, Antibiotic resistance in probiotic bacteria. Frontiers in Microbiology, 4. (2013) 1-6.

[19] Z. Gao et al., Inhibitory effect of lactic acid bacteria on foodborne pathogens: A review. Journal of Food Protection, 82. 3. (2019) 441453. 
[20] A. F. Jozala, L. C. de Lencastre Novaes, A. P. Junior, Nisin. In: Bobbarala, V. (ed.), Concepts, compounds and the alternatives of antibacterials. IntechOpen, London (2015).

[21] M. Laranjo, M. Elias, M. J. Fraqueza, The use of starter cultures in traditional meat products. Journal of Food Quality, (2017) 1-18.

[22] E. Laslo et al., Isolation and screening of lactic acid bacteria from naturally fermented sources with high biotechnological potential. Studia Universitatis Babeş-Bolyai, Chemia, 60. 4. (2015) 95-106.

[23] S. Leroy, I. Lebert, R. Talon, Microorganisms in traditional fermented meats (Chapter 12). In: F. Toldrá, Y. H. Hui, I. Astiasarán, J. G. Sebranek, R. Talon (eds.), Handbook of fermented meat and poultry. Wiley-Blackwell, Chichester (2015).

[24] R. E. F. Macedo, F. B. Luciano, R. P. Cordeiro, C. C. Udenigwe, Sausages and other fermented meat products. In: B. Speranza, A. Bevilacqua, M. R. Corbo, M. Sinigaglia (eds.), Starter cultures in food production, Wiley-Blackwell, Chichester (2017).

[25] R. Narayanan, K. T. Raghavan, Antibiotic susceptibility profile of lactic acid bacteria with probiotic potential isolated from humans. Biomedical Journal of Scientific \& Technical Research, 17. 4. (2019) 12964-12966.

[26] B. O. Olorunjuwon, B. K. Temitope, F. O. Muibat, Antibacterial activity of lactic acid bacteria isolated from fresh pepper and tomatoes against common food pathogens. Scientia Agriculturae, 4. 2. (2013) $42-47$.

[27] E. Papamanoli, N. Tzanetakis, E. Litopoulou-Tzanetaki, P. Kotzekidou, Characterization of lactic acid bacteria isolated from a Greek dry-fermented sausage in respect of their technological and probiotic properties. Meat Science, 65. (2003) 859-867.

[28] A. R. Patel, N. P. Shah, J. B. Prajapati, Antibiotic resistance profile of lactic acid bacteria and their implications in food chain. World Journal of Dairy \& Food Sciences, 7. 2. (2012) 202-211.

[29] M. M. Patil, P. Ajay P., T. Anand, V. K. Ramana, Isolation and characterization of lactic acid bacteria from curd and cucumber. Indian Journal of Biotechnology, 9. (2010) 166-172. 
[30] D. Ren, J. Zhu, S. Gong, H. Liu, H. Yu, Antimicrobial characteristics of lactic acid bacteria isolated from homemade fermented foods. BioMed Research International, (2018) 1-9.

[31] M. D. Selgas, M. L. García, Yeasts. In: F. Toldrá, Y. H. Hui, I. Astiasarán, J. G. Sebranek, R. Talon (eds.), Handbook of fermented meat and poultry. Wiley-Blackwell, Chichester (2015).

[32] V. P. Singh, V. Pathak, A. K. Verma, Fermented meat products: Organoleptic qualities and biogenic amines - A review. American Journal of Food Technology, 7. (2012) 278-288.

[33] B. Speranza, A. Bevilacqua, M. R. Corbo, C. Altieri, M. Sinigaglia, Selection of autochthonous strains as promising starter cultures for Fior di Latte, a traditional cheese of southern Italy. Journal of the Science of Food and Agriculture, 95. 1. (2014) 88-97.

[34] G. Vinicius et al., A review of selection criteria for starter culture development in the food fermentation industry. Food Reviews International, (2019) 1-33.

[35] S. A. Vurani, A. Godwin, N. U. Charity, C. E. Chinelo, G. Okafor, Antimicrobial activity of lactic acid bacteria from Kunun-Zaki on selected clinical pathogens. South Asian Journal of Research in Microbiology, 3. 4. (2019) 1-8.

[36] P. Zeuthen, Historical aspects of meat fermentations. In: G. CampbellPlatt, P. E. Cook (eds.), Fermented meats. Springer, Dordrecht (1995). 